\title{
The Names of Traditional Minahasan Food as Immune Booster in the Covid-19 Pandemic
}

\author{
Rina P. Pamantung ${ }^{1 *}$, I Nengah Sudipa ${ }^{2}$
}

\author{
${ }^{1}$ Universitas Sam Ratulangi \\ ${ }^{2}$ Universitas Udayana \\ * Corresponding author. Email: r.pamantung@yahoo.com
}

\begin{abstract}
The traditional food of Minahasa is viewed as one of the perpetual and prolonged cultures considering its sustainable and continuously growing lexicon along with the changing life dynamics of North Sulawesi communities, especially the Minahasa. This article aims to analyze the traditional Minahasan food as immune booster in the current Covid-19 pandemic period. Two research questions are being asked: 1). How is the naming system of traditional Minahasan food? 2). What is the lingual form related to the meaning of traditional Minahasan food as an immune booster in the Covid-19 pandemic period?. This research is conducted in the context of language and cultural preservation, especially in the intangible cultural heritage provision. The research uses descriptive qualitative method through ethnographic approaches and synchronic linguistic method, as well as the initial introduction of the gastronomic linguistic approach. The basic linguistic theory [1], [2], the theory of naming [3], and the meaning components theory [4], the supporting theory namely the gastronomic linguistic theory are used in the data analysis. The result found that the traditional Minahasan food naming system in the Covid-19 pandemic period is based on food ingredients, cooking methods, cooking utensils, food manufacturing locations, human names, and the creation of the food maker. The traditional Minahasan food is divided into linulut label (food that is put and cooked in bamboo) and non-linulut label (food that is not cooked in bamboo). The forms of traditional Minahasan food names consist of the following words: tinu'tuan, pedal, peraal, sende'en, midal, woku, gohu, and tinape. Meanwhile, the phrase consists of tinu'tuan wik-wik, tinu'tuan ampas ba, tinu'tuan tai minyak, woku blanga, woku daong, woku woka, and babi woku. The compound words are rica rodo, bob engka, and rintek wu'uk. Reduplications are rica-rica, lampu-lampu, and tinu'tuan wik-wik. The clause includes the names woku isi di bulu, ayang woku isi di bulu, and sayor pait isi di bulu. The meaning of traditional Minahasan food contains denotative and connotative meanings. Furthermore, the cultural meaning of traditional Minahasan food, on the one hand, is horizontally as a "blessing or gratitude" to Opo Ni Empung or God, who is the owner of the universe. Vertically, on the other hand, it is an effort or thanksgiving for the achievement of work or a blessing from the food maker or any individual who has a thanksgiving ceremony.
\end{abstract}

Keywords: Traditional Minahasan food, immune booster, naming system, and gastronomic Linguistics

\section{INTRODUCTION}

Food and language are distinctively interconnected cultural heritage in most cultures. Fitrisia and Ritonga [5] highlight that "Food is generally to be consumed, but it is through language that we will know how it is made, what ingredients are used in a recipe, the meaning of the name of the food, as well as the culture of each community concerning food such as eating together." Concerning this, Geertz (1973) points out that the core of culture is culinary because every discussion that circulates and/or is related to culture will eventually include culinary, hence it seems to be the essence of culture. In the Minahasa community, the names of traditional Minahasan food are considered to have a peculiar mixture of the forms of language and emotion that boldly differentiate themselves from a telephone directory that consists of numbers and addresses, for instance, which does not seem to have any emotion. Its cuisine is simply not only about food consumption to get rid of hunger but also encompasses many aspects of humans' lives, including emotion. Furthermore, Fitrisia and Ritonga [5] also add that "....culinary is matters relating to cooking, food, and drinks as a basic need for human beings as well as energy sources for daily 
activities." In this regard, the realm (situationcondition) of cross-cultural culinary knowledge and experience is highly significant in understanding the traditional food of the Minahasa community in the Covid-19 pandemic. This research entitled "The Names of Traditional Minahasan Food as Immune Booster in the Covid-19 Pandemic" focuses on two main questions: 1). How is the naming system of traditional Minahasan food? 2). What is the lingual form related to the meaning of traditional Minahasan food as an immune booster in the Covid-19 pandemic period?.

Another worth-noted aspect of culinary is its importance as an integral part of food security. Food and Agriculture Organization (FAO) writes that "food security exists when all people, at all times, have physical, social and economic access to sufficient, safe and nutritious food to meet their dietary needs and food preferences for an active and healthy life. The four pillars of food security are availability, access, utilization and stability. The nutritional dimension is integral to the concept of food security." (2009, 1). Thus, basic knowledge about culinary is necessary for survival in certain difficult situations, such as in the global pandemic period. The current global Covid-19 pandemic causes people around the world to experience limited space and difficulties in terms of fulfilling their daily primary needs, such as food. Independent isolations, losing jobs and working from home are the current states that contribute to this issue. More ironically, this pandemic situation requires prevention efforts of each individual from the spread of the virus, including the fulfilment of a balanced nutritional diet. Martanto, in an online national seminar at Manado in 2020, argues that the traditional Minahasan food contains protein and other nutritionally balanced substances. Those can be seen from the ingredients, seasonings and the mixture of spices that are used in the making of traditional food of the Minahasa community. One of the popular Minahasan spices is called 'Rampa campur' (Mixed spices) that is believed to have balanced nutrition, which seems to be able to contribute to the prevention of the spread of Covid19.

Furthermore, the traditional Minahasan food is one of the longstanding cultural assets for the Minahasa community, which survives to these days, but with the emergence of lexicon variations and modifications, that continue to increase in the names of the traditional Minahasan food. This tendency follows the trend of the continuously growing names of traditional food in the Minahasa community. To this, various names emerge resulting from the word combinations and modifications. The empirical facts nowadays, however, seem to show the ambiguity and overlapping in the appearance of traditional Minahasan food's names in the feasts' menu list and those listed in restaurants, hotels and inns, and vendors. In the local feast namely 'Endo Wangko' (Manado malay: 'pangucapan' and English: 'Big $\left.D a y^{\prime}\right)$, which is an indigenous annual feasting ceremony of the Minahasa community, on the one hand, the names of Minahasan traditional foods initially contain indigenous religious functions. On the other hand, slightly similar names of traditional Minahasan food are also commercialized in the other dining locations as the regular menu without any significant cultural values. To these issues, it is crucial to analyze and reassert the meaning and functions of the names of traditional Minahasan food in the context of language and cultural preservation, especially in the intangible cultural heritage provision.

\section{METHODOLOGY}

This research uses the basic theory of linguistics such as morphology [1], and syntax and theory of meaning [7]; [6]. Word theory is an indivisible form. Word consists of a free morpheme or bound morpheme [1]; [8]; while the phrase is a combination of several words that have a core (head) and an explanation (modifier), [2]. Moreover, Leech [7] pinpoints that the meaning consists of denotative and connotative meanings. The denotative meaning is the true meaning of the word, while the denotative meaning is the same as the conceptual meaning. The connotative meaning is the meaning outside of the true meaning such as the figurative or metaphorical meaning of the word.

Meanwhile, the contextual cultural meaning by Van Dijk (1998) is used in this research. It is argued that the context is viewed as a textual background that is subjective, and dynamic. It exists in a mental structure that is based on social knowledge, and is a manifestation of situations and as a cultural variable. Context is subjective as opposed to previous understanding of the objectivity of the social context. The constraints of context are not only on social variables such as gender, social strata and other structured things but rather on autobiographical representations in episodic memory. This is related to the mental structure of language use, including the language of ritual. The mental aspect is the way people are involved in adapting or understanding every fragment of discourse in a communication event. Context is also positioned as one of the pragmatic sides of cultural discourse.

Furthermore, this research also uses another van Dijk's theory namely ideological theory (van Dijk, 1998). This theoretical approach adopts the paradigm of social cognition, social science, and discourse. In discourse, the function of ideology is related to text and speech. This relationship places ideology in a structured system that can be expressed by a specific intonation, volume, clause structure 
(transitivity: active and passive), specific lexical selection and use, impregnation, presupposition, coherence, overall topic, rhetoric (metaphor), schemata, selection of speech events, and language politeness.

In addition, this research uses the qualitative method through an ethnographic or ethnomethodological approach at the linguistic level called the synchronic descriptive approach. Another approach that is also used in this research is the linguistic gastronomy approach. These approaches are applied in the data collection and analysis; hence the illumination of the meaning of the traditional Minahasan food's names will suit the cultural perspective of the Minahasa community as the focused subject of this research. Therefore, it seems obvious that this research is conducted in the realm of anthropolinguistics or ethnolinguistics research.

Moreover, the naming system in word form or lexeme of the traditional Minahasan food signifies both linguistic and cultural meanings through lexical relations. The search for linguistic elements mentioned before is analyzed in the naming of traditional Minahasan food. This research focuses on the informants of the Minahasa community in two conducted areas, which are Manado city and Minahasa District. The data are primarily collected through field and participant observations and interviews. The sample selection is based on purposive sampling, which is later adjusted accordingly to the research need. As also mentioned before, the data are linguistically analyzed using the morphological theory [1], [8], syntax (Givon, [2]) and the theory of meaning [7].

\section{ANALYSIS}

As mentioned before, this research entitled "The Names of Traditional Minahasan Food as Immune Booster in the Covid-19 Pandemic" rises two focused research questions: 1). How is the naming system of traditional Minahasan food? 2). What is the lingual form related to the meaning of traditional Minahasan food as an immune booster in the Covid19 pandemic period? This research found the results that will be discussed and elaborated on as follows.

Naming systems and lingual forms of the names of traditional Minahasan food as an immune booster in Covid-19 pandemic.

Mythologically, the concept of culture of the Minahasa community in the context of naming systems of traditional Minahasan food includes references to talun (forest) and uma (garden). They arguably have cultural and cognitive meanings that raise the series of several components of meaning which function as the parameter factors in the naming systems that influence the emergence of traditional Minahasan food names. Those components are 1). Food ingredients 2). Cooking methods 3). Food manufacturing locations 4). The background of local language use in Minahasa 5). History of the arrival of Minahasa ethnicity and its language and 6). Humans (Minahasa community itself). The traditional Minahasan food commonly consists of rice and vegetables flavoured with rampa campur (mixed spices) such as basil, green onions, lemongrass and salt.

The names of traditional Minahasan food that are featured in menu are kaan, sende'en, dan serza. They are categorized as Linulut and non-Linulut lebels. The linulut label is traditional Minahasan food that is put and cooked inside the bamboo, while the non-linulut label is the food that is not cooked inside the bamboo. Meanwhile, the lingual forms of traditional Minahasan food are signified in words, phrases and clauses of the local language of the Minahasa community. In words, the traditional Minahasan food consists of tinoransat, pangi, sa'ut, $R W$, kawok, paniki, batman, kokole, ambal, koles, sende 'en, kinetor, tinutu'an, peda'al, pera'al, ti'nei, sinegor, bobengka, and eveready. In phrases, the names are sayor pa'it, babi leilem, babi woku, woku daong, woku blanga, woku woka, dari tinu'tuan wik-wik, tinu'tuan ampas ba, tinu'tuan tai minyak, lampu-lampu,ular patola woku, and rica-rica; while in clauses, there are ayang leilem isi di bulu, ayang woku isi di bulu, and sayor pa'it isi di bulu. In terms of reduplication, moreover, the names of traditional Minahasan food include lampu-lampu dan rica-rica.

The meaning of the names of traditional Minahasan food as an immune booster in Covid-19 pandemic

The names of traditional Minahasan food as an immune booster in the Covid-19 pandemic have denotative and connotative meanings. The denotative meaning is found in various food names such as pangi, sa'ut, RW, kawok, Ayang woku isi di bulu and paniki. Most food names are derived from the names of ingredients used in food dough and processing. The connotative meaning is shown in the food names such as bobengka which means female gender and Eveready is the name of food processed from cat meat, therefore it is equated with an image of a cat on one particular battery brand. Moreover, sende'en means women who are not good and brot goreng means a distinctively irregular shaped cake which is viewed to be slightly similar to the annoyed facial expression of an ugly person.

The concept of culture in traditional Minahasan food is signified in the forms of language and the cultural meaning which has been reduced to religious/belief symbols as 'blessing' and/or 'thanksgiving (gratitude)' as the implied meaning. This includes a social system because the remaining culinary tradition in the modern Minahasa community is the habit of eating the menu of the 
traditional Minahasan food as a daily routine for social mobility.

As it is viewed from the cultural realm, it is also argued that, in the past, the traditional Minahasan food was closely tied to the indigenous belief system of the Minahasa community, which used to function as the 'mediator' between humans and Opo Niempu, the owner of the universe. This function undergoes a dynamic spiritual transformation into a symbol of 'blessing (gratitude)'. Therefore, it seems obvious that the role of traditional Minahasan food is closely related to the current cultural understanding of the Minahasa community in feasting and non-fasting food consumption which is expressed in the uses names traditional Minahasan foods.

\section{CONCLUSION}

Names are uniquely adopted and created, and to some extent, have a significant meaning, which represents another meaning. In the Minahasa community, the naming system of the traditional Minahasan food is distinctively based on the food ingredients, cooking methods, cooking utensils, food manufacturing locations, human names, and the creation of the food maker. The lingual forms of the names of traditional Minahasan food as immune booster are found in the words, phrases, and clauses.

In addition, the meaning of the traditional Minahasan food names contains denotative and connotative meanings. On the one hand, the cultural meaning of traditional Minahasan food is horizontal as a "blessing or gratitude" to Opo Ni Empung or God, who is the owner of the universe, while vertically, on the other hand, it is an effort or thanksgiving for the achievement of work or a blessing from the food maker or any individual who has a thanksgiving ceremony.

\section{ACKNOWLEDGMENT}

First of all, Thank you to Almighty God. We are extremely great. We also would like to say thank you very much to all those people who have given us motivation, encouragement, and advice. Thank you also to Atalantis Star for accepting the articles. Finally, we hope the articles can be useful for the readers.

\section{REFERENCES}

[1] Katamba. (1993). Introduction to Morphological Structure. London: The Macmillan Press

[2] Givon, T. (1984). Syntax: A Functional Typological Introduction. Amsterdam/Philadelphia: John

[3] Palmer, E. (1976). Semantics. Great Britain: Cambridge University Press.
[4] Lehrer, A. (1974). Semantic Fields and Lexical Structure. Amsterdam: North Holland Publishing Company

[5] Fitrisia, D., Sibarani, R., \& Ritonga, M. (2018). Traditional food in the perspective of culinary linguistics. International Journal of Multidisciplinary Research and Development, 5(2), 24-27.

[6] Lyons, J. (1977). Semantics. I - II. Cambridge: Cambridge University

[7] Leech, G. (1981). Semantics. London: Penguin Books.

[8] Matthews, P.H. (1978). Morphology: An Introduction to the Theory of the WordStructure. London: Cambridge University Press. 